The 9th International Symposium on Automation and Robotics in Construction June 3-5, 1992 Tokyo, Japan

\title{
DEVELOPMENT OF SYSTEM CAPABLE OF SPRAYING FIREPROOF COVERING MATERIALS
}

\author{
Hitoshi Miyamoto, Yukihiro Watanabe, Shoichi Morimoto \\ ; Development Office, Plant Equipment Department, \\ Civil Engineering Devision, Fujita Corporation \\ Tokio Sawada ; Technical Consultancy Department, \\ Building Construction Devision, Fujita Corporation \\ Ryoji Yoshitake ; New Production System Development Department \\ Building Construction Devision, Fujita Corporation \\ Junichi Iimori ; Technical Consultancy Office, Building Construction Department \\ Yokohama Regional Office, Fujita Corporation \\ 4-6-15 Sendagaya, Shibuya-ku, Tokyo, 151, Japan
}

\begin{abstract}
As one of the approaches to promote further unmanned construction work using industrial robots for general application, we have developed a robot system capable of spraying fireproof covering materials. The proposed robot system consists of a robot, a control panel, an automatic carriage with a lift, and a gang control plant. Through a trial construction using the robot system at an actual building construction site, we were able to ensure that the robot system enables sprayers to be freed from the physical and mental burdens which result from the generation of dust while fireproof covering materials on structural members are being sprayed, as well as allows for a reduction in labor, and an improvement in working speed, and ensures a high quality of construction.

This paper will describe the background and evolution of the development of the robot system, an overview of the system's equipment, an operational rundown, the methods used for the system's development, the procedure used for trial construction, and development of the system in the future.
\end{abstract}

\section{INTRODUCTION}

In recent years, with the demand for building construction increasing rapidly, steel framings which allow for field construction with a relatively small labor requirement have been adopted more extensively than ever before. The consequence of this has been an increase in the amount of work required to spray fireproof covering materials. It has also become very difficult to find young laborers to do this job as the work of spraying fireproof covering materials is performed in a harsh environment, therefore much of the work has had to be carried out by those of a more advanced age, and the industry as a whole is suffering from the shortage of labor and skilled technicians.

This robot system aims at eliminating such field handicaps by spraying field-mixed materials by using the dry method, which shares in over $90 \%$ of the amount of work required to spray fireproof covering materials.

In developing the robot system, a project team composed of members from machine manufacturing companies as well as a speciality contractor, was organized. The development of the robot system was promoted through a repeated cycle of system buildup (including improvements and modifications), basic experiment, and trial field construction. 


\section{SYSTEM'S EQUIPMENT OVERVIEW}

Fig. I briefly illustrates the system's constituent equipment.

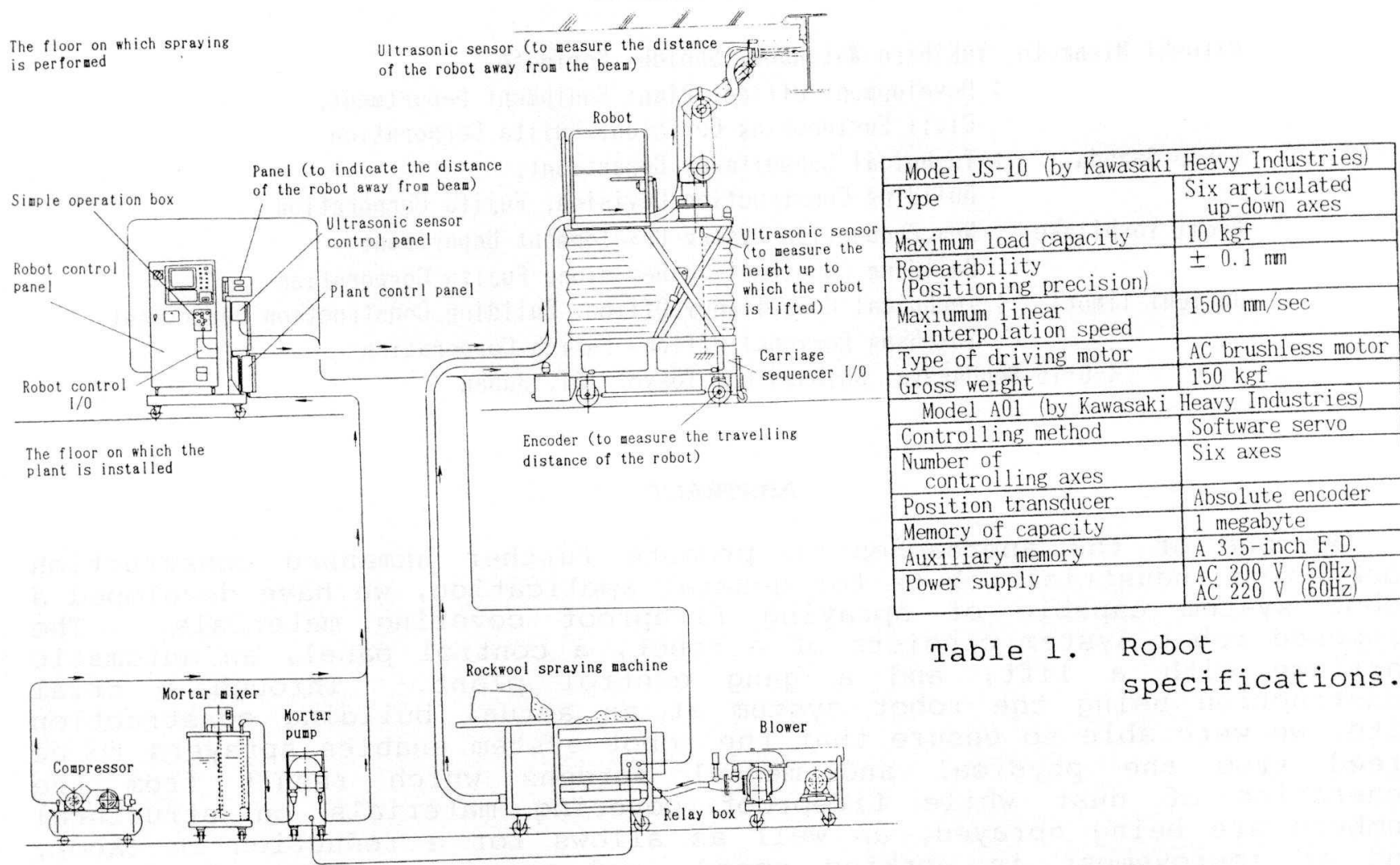

Fig. I The constituent equipment configuration of the system.

\subsection{The Robot and its Control Panel}

With this system, the robot uses six vertically articulated axes for industrial use which are available on the market. The panel to control the robot proper is equipped with a panel display which has a programming function. Table 1 shows the main specifications of the robot proper, Fig. 2 illustrates the robot's working range, and Fig. 3 illustrates the control panel on which the peripheral instruments and equipment are mounted.
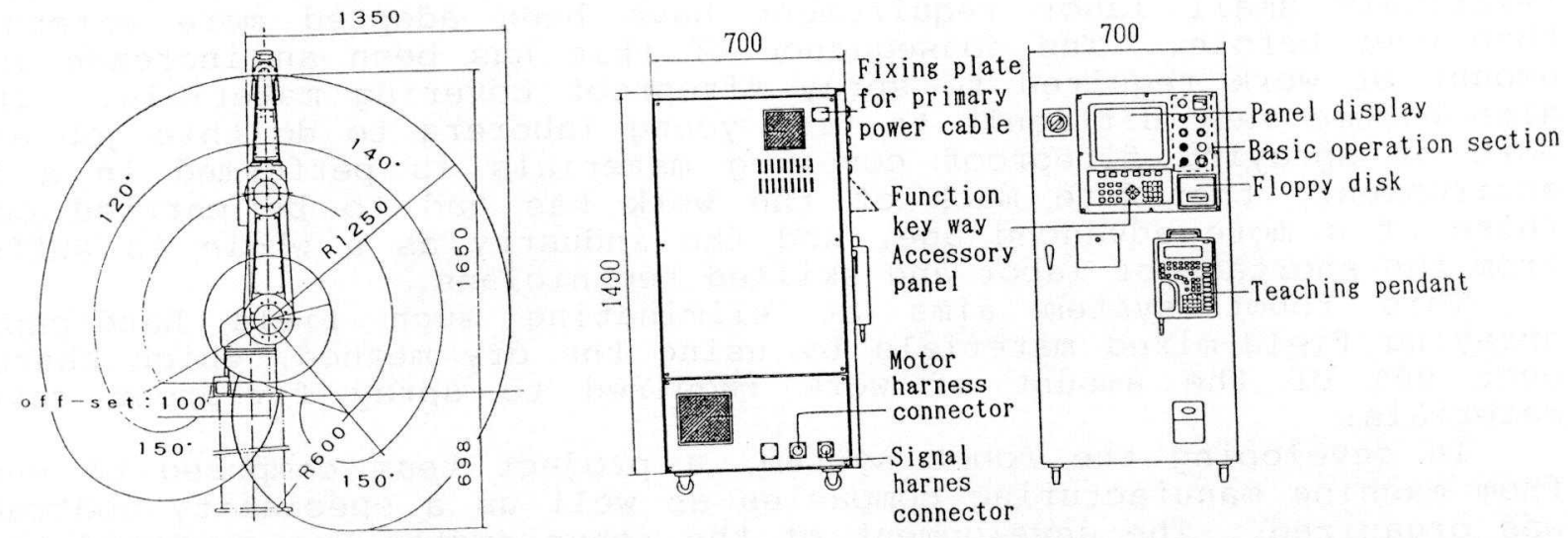

Fig. 2 Robot's working range.

Fig. 3 Control panel. 


\subsection{Automatic Carriage with a Lift}

The carriage required to provide the robot with an exclusive travelling function was developed jointly with the manufacturer, and is designed so that it is interconnected, and is able to automatically travel, with the robot, as well as also be operable from a remote place. With the robot remaining inoperable, the carriage allows for a person to perform work on it. Fig. 4 outlines the carriage and Table 2 gives its main specifications.

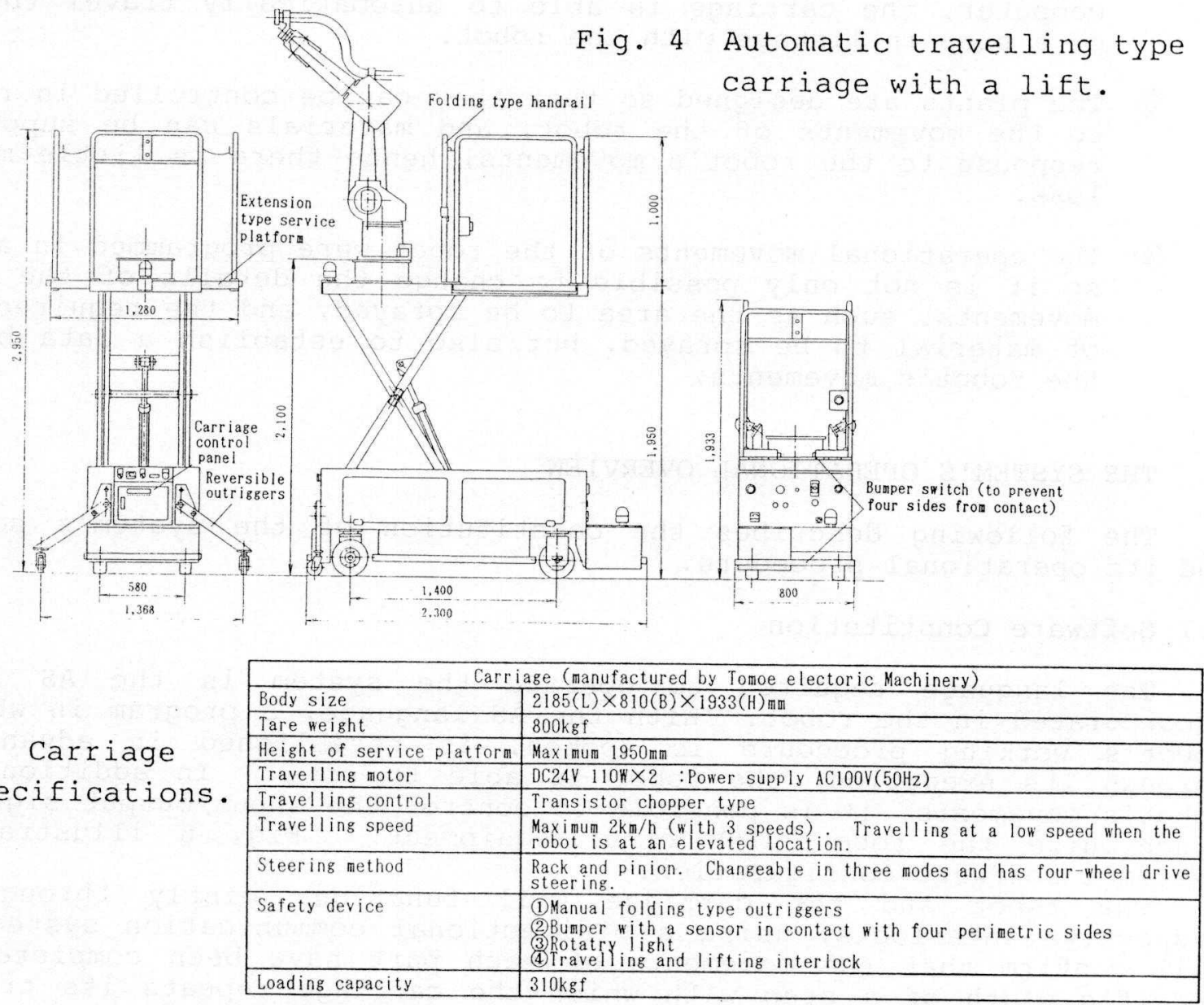

\subsection{Gang Control Type Plants, and Spray Gun}

Plants (a rockwool spraying machine, a blower, a mortar pump, a mortar mixer, and a compressor) which were used for spraying fireproof covering material, and which are available on the market, were purchased, and then modified in order for them to be able to interlock the robot. Table 3 describes the modifications the plants underwent.

The spray gun used with this system had eight holes as shown in Fig. 5 , and was modified to change the spraying focal distance $f r o m ~ 50 \mathrm{~cm}$ to $60 \mathrm{~cm}$, thereby expanding the working range of the robot.

\begin{tabular}{|l|l|c|c|}
\hline Name of machine & $\begin{array}{l}\text { Rockwool spraying } \\
\text { machine }\end{array}$ & \multicolumn{1}{|c|}{ Roots blower } & Motar pump \\
\hline $\begin{array}{l}\text { Modification } \\
\text { effected }\end{array}$ & $\begin{array}{l}\text { Changed the control } \\
\text { signal from AC 24V } \\
\text { to DC 24V }\end{array}$ & $\begin{array}{l}\text { Changed the method of air velocity } \\
\text { adjustment so that the frequency can } \\
\text { be controlled with an invertor }\end{array}$ & $\begin{array}{l}\text { Changed the control } \\
\text { signal from AC 24V } \\
\text { to DC 24V }\end{array}$ \\
\hline
\end{tabular}

Table 3. Main specifications and modifications of the gang control type plants.

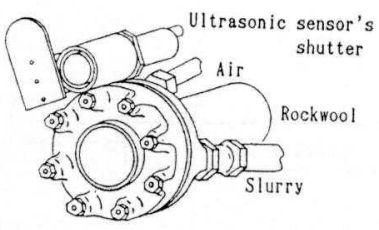

Fig. 5. 8-hole type spray gun. 


\subsection{Features of the System}

(1) By using the industrial robot for general application, the robot will not need to be repaired as often.

(2) Sophisticated manipulation of the robot's carriage is feasible because of the travelling mode changing system which enables steering with four wheels and two wheels respectively, and traversing at angles of 90 degrees. Furthermore, with a mounted computer, the carriage is able to automatically travel the width of a step in linkage with the robot.

(3) The plants are designed so that they can be controlled in response to the movements of the robot, and materials can be supplied in response to the robot's movements, hence there is little material loss.

(4) The operational movements of the robot were programmed in advance, so it is not only possible to change the details of the robot's movements, such as the area to be sprayed, and the required amount of material to be sprayed, but also to establish a data base for the robot's movements.

\section{THE SYSTEM'S OPERATIONAL OVERVIJW}

The following describes the constitution of the system's software, and its operational procedure.

\subsection{Software Constitution}

The language required to operate the system is the AS language incorporated in the robot. With the AS language, a program in which the robot's working procedure is spoken, is established in advance, and through its execution, the robot is able to move. In addition to the robot's movements, it is possible to control the input/output signals and synchronize the robot with other equipment. Fig. 6 illustrates the system's software configuration.

The robot and the carriage will function jointly through their respective interlocks, using a bidirectional communication system, which will confirm that the movements of each part have been completed. The specific width of a step with which the carriage repeats its travelling and stopping functions in response to the spraying width of the robot, has already been inputted into the carriage. The width of a step is detected by the encoders mounted on the wheels of the carriage, and is readable through the computer mounted on the carriage.

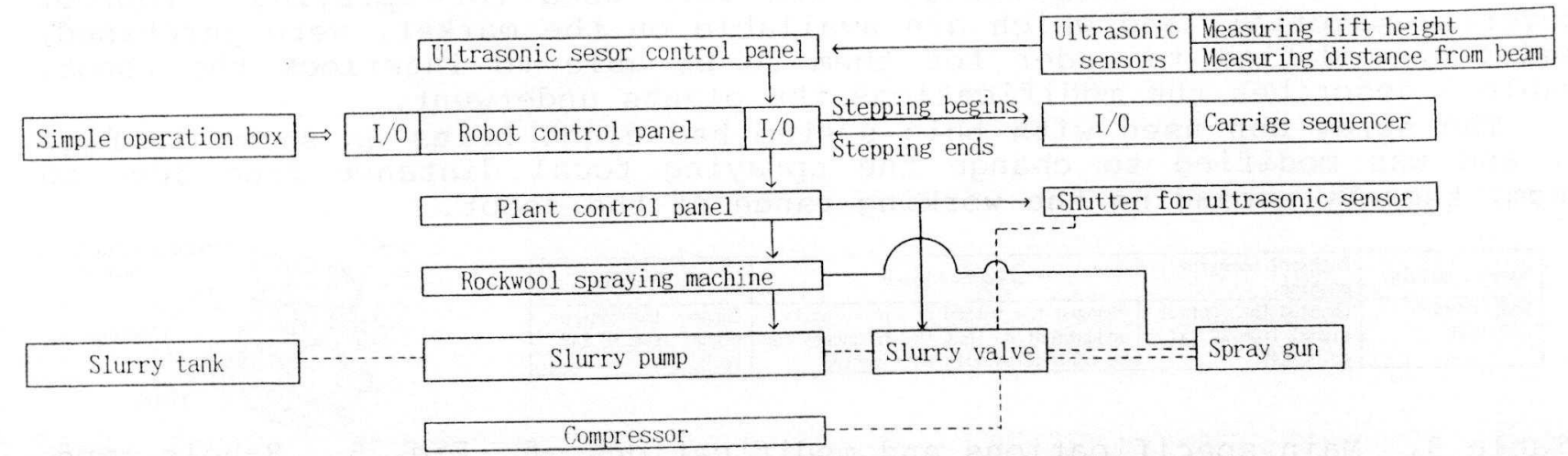

Fig. 6. The system's software configuration. 
Conversely, the rockwool spraying machine functions are in linkage with the mortar pump through their respective interlocks, against an unidirectional ON/OFF command transmitted one-sidedly by the robot. In other words, the machines are controlled using the timer stored in the robot's software, thereby completely synchronizing the machines with the spraying movements of the robot. The timer setting which is incorporated as the data base of the robot resulted from the measurement of various spraying positions. Fig. 7 shows the time chart of the robot's software.

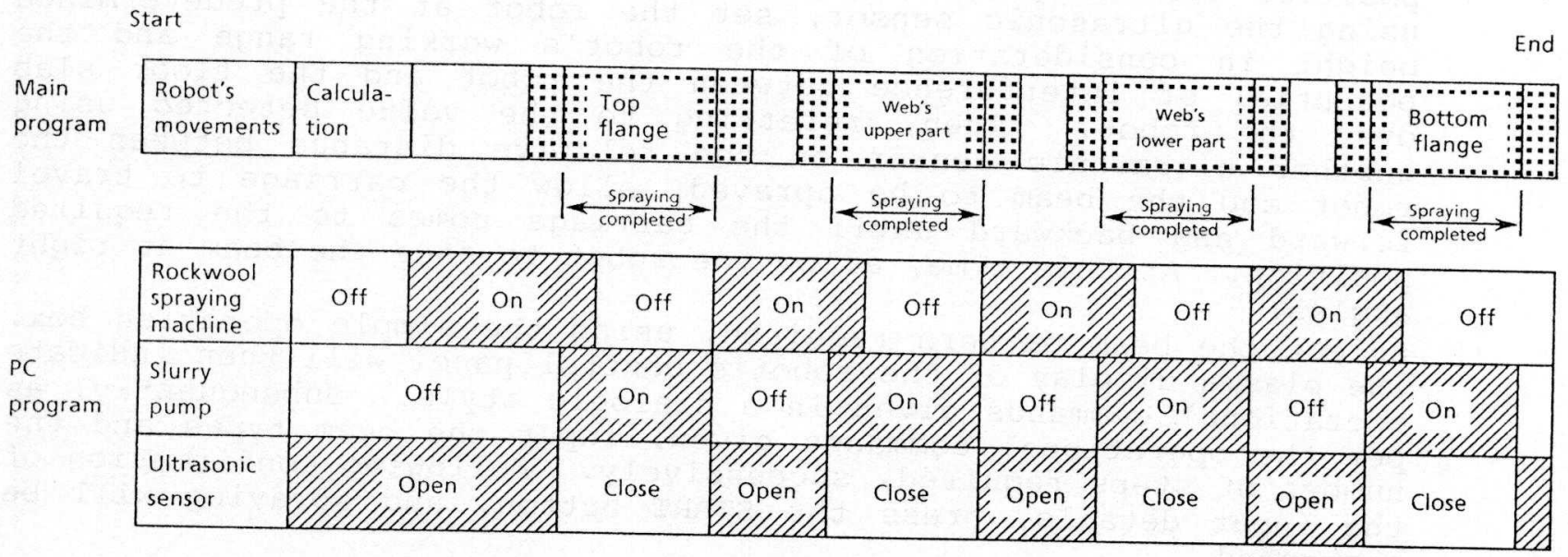

Fig. 7. Time chart of the robot's software.

\subsection{Operational Procedure}

The following describes the system's operational procedure. Fig. 8 is a chart showing the flow of the operational procedure.

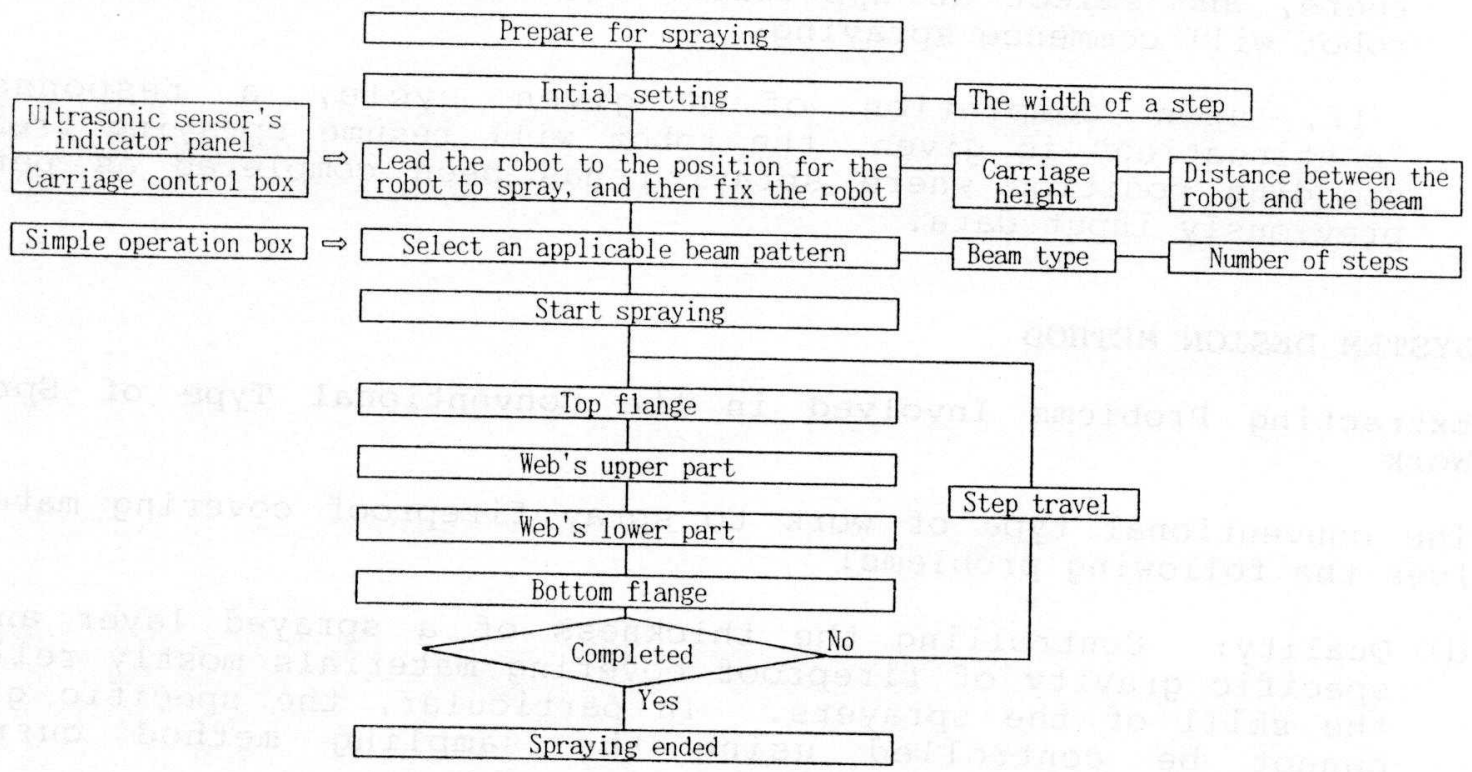

Fig. 8. Operational procedure. 
(1) Input the width of the step initially set, into the carriage. This width should be the width of the fireproof covering material to be sprayed by the robot, and has already been established as the data base.

(2) The functions of guiding the robot to the position required for The functions of guiding the robot the
the robot to perform spraying, and the subsequent setting of the
robot, are carried out by hand. First, guide the robot to the position for spraying. Second, referring to the value detected using the ultrasonic sensor, set the robot at the predetermined height in consideration of the robot's working the floor slab potential of interference between to the value detected using over the robot. Then, on the relative distance between the another ultrasonic sen to be sprayed, allow the carriage to travel robot and the beam the required forward and backward untilow the robot to face the beam at right position. At this time, allow angles.

(3) Select the beam pattern required, using the simple operation box. The plasma display of the robnt's control panel will then indicate operational commands given in a dialogic style. Subsequently, as per the operational commands given, input the beam types and the number of steps required, successively. Following confirmation of the input details, press the START button, and spraying will be commenced.

(4) When the spraying with the robot continuously stepping forward in accordance with the given cycle has been completed, the robot will ask if the given operation should continue or discontinue. If a response of "discontinuation" is given, the robot program returns to "Beam Pattern Selection." During this period, the robot will remain motionless in a position where spraying operation can be started, to wait for the next command. Therefore, guide the robot to the subsequent position for spraying operations, fix the robot there, and select an applicable beam pattern again so that the robot will commence spraying.

If, upon completion of a given cycle, a response of "continuation" is given, the robot will resume spraying from its standing position where spraying has been completed as per the previously input data.

\section{SYSTEM DESIGN METHOD}

4.1 Extracting Problems Involved in the Conventional Type of Spraying Work

The conventional type of work to spray fireproof covering materials involves the following problems:

(1) Quality: Controlling the thickness of a sprayed layer and the specific gravity of fireproof covering materials mostly relies on the skill of the sprayers. In particular, the specific gravity cannot be controlled using the sampling method currently practiced.

(2) Costs: There is a large material loss during spraying work, therefore the ratio of material cost to labor cost is great. 
(3) Progress in work: The amount of time actually worked in a full day is short.

(4) Safety: Sprayers must wear dust respirators and rain outfits in order to proceed with spraying work in an adverse environment, and must also perform work mostly from the rolling towers installed at elevated locations.

\subsection{Establishment of Functions and a Master Alternative, for the System}

Based on the idea that a premixed fireproof covering material is sprayed onto the surface of the designated steel members by a person holding a nozzle, the system's development was initiated upwards and downwards, and a function which enables the steel member's surface to be covered with such a material in a layer thickness exceeding the designed one was established.

Furthermore, an alternative which precludes fireproof steel materials having the required fireproof qualities, as well as twenty kinds of alternatives which result from the various methods (dip brazing, paint application, spraying, sheet application, and board application) multiplied by the work execution places (steel fabrication shops, offsite workshops, on-site workshops, and on-site assembly area), were established, and with quality improvement, cost reduction, work schedule reduction, safety improvement, and technical potential (in mechanical and architectural areas) adopted as items for evaluation, the master alternative was evaluated. As a consequence, the method of spraying a fireproof covering material on steel members at the place where they are assembled was adopted as the master alternative.

\subsection{Dividing of Components}

The method of spraying a fireproof covering material on steel members at the place where they are assembled, which is the system's master alternative, was divided into the components which constitute this method, and the individual components were further subdivided as shown in Fig. 9 .

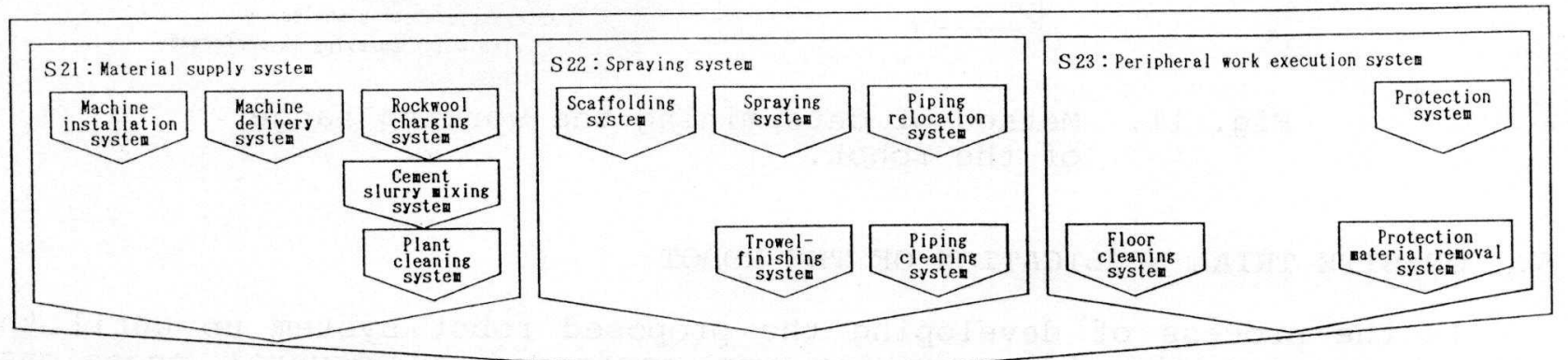

Fig. 9. Components of the system's master alternative

\subsection{Work Analysis}

Analysis of the system's design work was conducted when it reached the stage in which the division of the components had been completed. The main reason we analyzed this work was because investigation requirements had already been clarified, therefore sophisticated investigations had become feasible and the design of the machines and equipment involved required the basic data in order to allow system design. This work analysis was conducted at three construction fields located in different areas. 


\subsection{Determination of Specifications for the Equipment and Machines that Constitute the System}

The components which had been divided as mentioned in section 4.3 were further subdivided, the functions were then combined for persons and machines, and based on the results of work analysis, the specifications of the machines and equipment which constitute the system were determined. As an example, the robot's skeletal selection process will be outlined below.

The machines required to perform spraying motions were composed of a general use type industrial robot with teaching and playback functions, and a carriage interlocked with the robot which had an automatic lift. Consequently, based on the results of the work analysis which was described in section 4.4, the skeletal system of the robot was determined. In full, the number of axes required for the robot was determined through an analysis of the motions illustrated in Fig. 10, and this was followed by a determination of the working range of the robot as ilustrated in Fig. 11 .

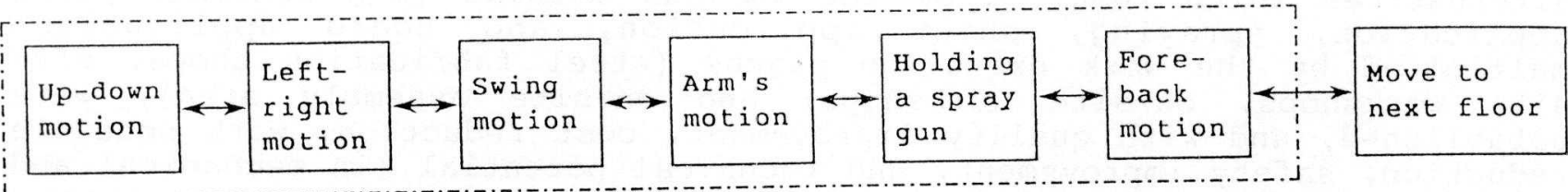

A vertical, articulated type robot with six axes will perform motions equal to those shown above.

Fig. 10. Analysis of the motions of a person engaged in the work of spraying a fireproof covering material.

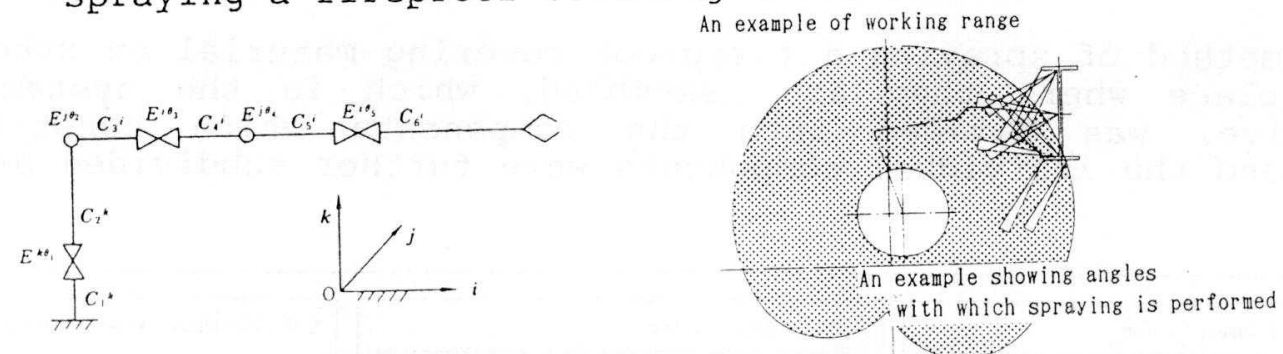

Fig. 11. Method of determining the working range of the robot.

\section{ON-SITE TRIAL APPLICATION OF THE ROBOT}

In the process of developing the proposed robot system up until the present stage, laboratory testing was performed on several occasions. This was followed by tests performed at actual construction sites.

\subsection{Sequence of Robot's Spraying Motions}

In the case of the traditional, manned method of spraying rockwool on beams, the so-called vertical spraying method, in which a sprayer sprays rockwool by moving a spray gun up and down in a way in which the line of the previously sprayed course will be overlapped by a subsequent course being sprayed at a certain angle, has been used. In contrast, the proposed method of spraying with the robot is the so-called horizontal spraying method, in which the robot sprays rockwool by swinging the spray gun in its hand in a horizontal direction. This motion is characteristic of the robot due to its skeletal system as well as to the step-travel of the carriage. Fig. 12 illustrates the sequence of spraying by the robot. 

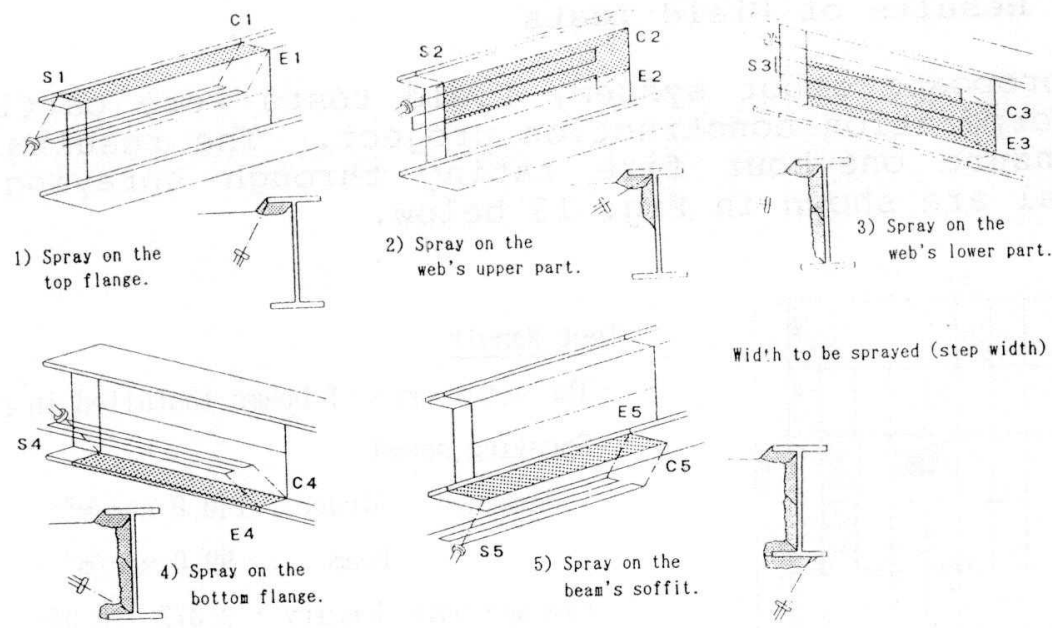

Wid h to be sprayed (step width)

Fig. 12. Sequence of spraying on a beam using the robot.
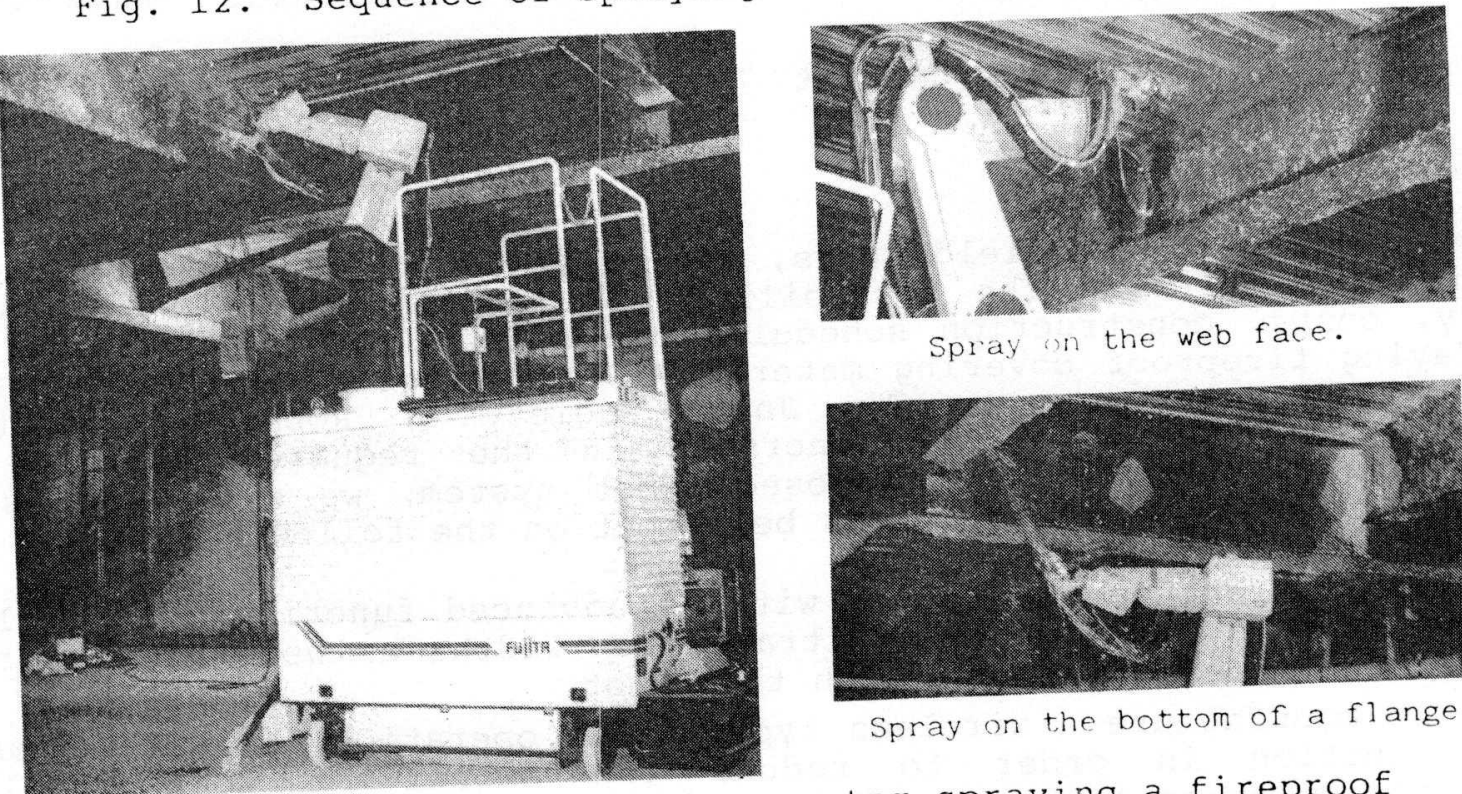

Spray on the web face.

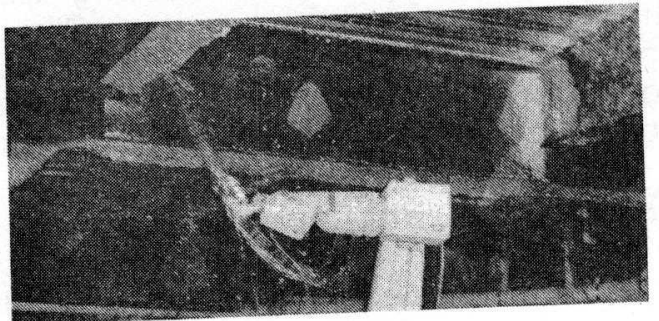

Spray on the bottom of a flange.

The view of the robot system spraying a fireproof covering material.

\subsection{Settings for the Spraying Motions of the Robot}

The thickness and uniformity of a sprayed layer depends on how the three elements of the robot's motions; speed, accuracy (the radius of an inscribed circle at a point where the motion trajectory of the robot and the shifting width, relate to each other. Table 5 for the individual motion elements, which were used exemplifies settings for site of Fujita corporation.

Table 5. Examples of settings for individual motion elements

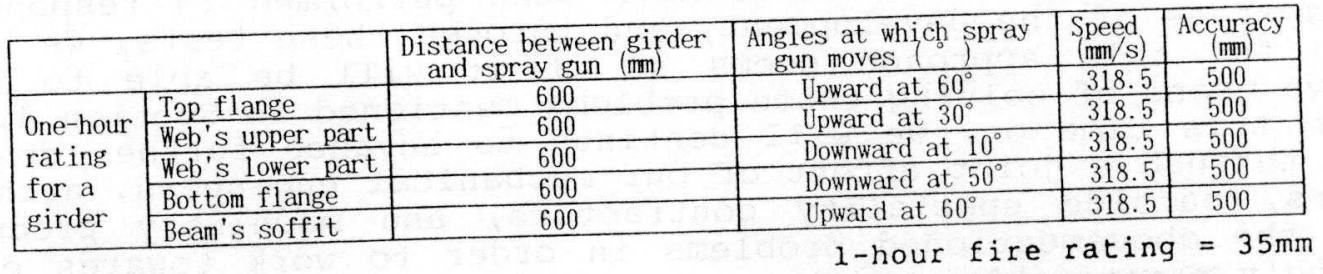




\subsection{An Example; Results of Field Tests}

Using the proposed robot system, field tests were carried out at an actual Fujita corporation construction project. The results of the tests performed to ensure one-hour fire rating through spraying a fireproof covering material are shown in Fig. 13 below.

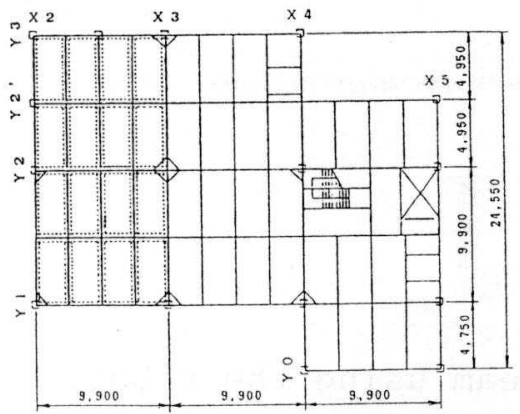

Test Result

- The total area of beams installed in place: $219.64 \mathrm{~m}^{2}$

- Spraying speed :

Unmanned - Girder : $140.0 \mathrm{sec} / \mathrm{m}^{2}$

Beam : $99.0 \mathrm{sec} / \mathrm{m}^{2}$

- Average bulk density : $0.372(>0.34)$

- Average thickness of sprayed layers : $36.6 \mathrm{~mm}(>35 \mathrm{~mm})$

Fig. 13. Range of spraying test

\section{FUTURE DEVELOPMENT}

As a result of the field tests, the proposed robot system has proven that it could provide the possibility of creating great advantages in quality, costs, construction schedule, and safety. Also, with the work of spraying fireproof covering materials increasing by approximately $20 \%$ in the last year (source: The Japan Society of Rockwool Industry), thereby suggesting a further increase in the requirements for even greater developments in the proposed robot system, we will continue to forward the development with focus being put on the following points:

(1) To manufacture a carriage with an advanced function, which allows itself to travel with arbitrary step widths as well as to perform interlocked operations with the robot.

(2) To manufacture a wireless type simple operation box with a multifunction in order to reduce the amount of work involving equipment-to-equipment signal cabling.

(3) To simplify the spraying plants as well as to ensure stable material supply.

(4) To simplify work involving the preparation of basic data, through the introduction of EWS simulation software.

\section{CONCLUSION}

As the first approach for the development of unmanned construction technology using a general application type industrial robot, the development of a robot capable of spraying a fireproof covering material has already begun. Field tests have been performed in response to the progress stage of the development, and through these tests, we have found that so far this approach seems as if it will be able to become an effective means of solving those problems mentioned in section 4.1.

From this time on, we will continue to advance further development, en bloc through a joint effort of our mechanical engineers, architectural engineers, outside speciality contractors, and machinery producers, to address the abovementioned problems in order to work towards creating a more highly practicable system. 